\title{
Think Globally Act Locally
}

Academic Medicine is gaining moment in the country. The culture of research and writing scientific article is limited to very few in most of the developing countries. Those who have made international publication are mostly with the joint venture. It is speculated that if a person from developed country becomes the co-author, article acceptance rate is increased in the international journals. That might be the reason why we rarely see author from our part with independent article. Due to low visibility, those kinds of author rarely publish in the local journal. Having so much experience in scientific writing, what these authors have contributed for the local journal is a question.

The new author coming up but the most important concern and more than that is "How to get a paper published?"1 There are people who are good at scientific writing and have the potential to help the academic medicine in Nepal. They always think of big journal seldom for local journal, which are raising standard of local scientific community. Unless and until we develop the culture to love our own parameters, we'll never improve. If we have the potential to change the way, we ought to come forward and join hand together.

It is always easy to criticize but more difficult to get along with it. The value of academic medicine is increasing day by day. If we do not develop the culture of improving the knowledge of editor, author and peer reviewer it will be very hard to improve the quality of scientific community. Even if a small steps is taken, they day is not far away to have improved academic medicine even in developing country. The future effort should be focused to train author, peer reviewer and current or prospective editors at local level. The general and specialty journal have come up to raise the standard of academic medicine in the country. However, the journals have to be supportive, helpful and guide authors for their manuscript preparation, addressing peer reviewers' comments and encourage submitting the articles. ${ }^{2}$

Recent changes in the rules and regulations in the institutes has call indirectly for improvement in journal to check the quality of submitted researches which help authors to have academic achievements. ${ }^{3}$

At present, we are in the zone of transition to start a new era of academic medicine in Nepal. One group is established, more experience and holds the key positions in the community while another is rapidly growing young medical community which is updated, smart, energetic and to faces the challenge of the competitive modern world. ${ }^{4}$ The identification of potentials individual who could contribute to the scientific community has been started by local journal. ${ }^{5}$

Similarly, the culture of appreciating local endeavor is still far away. However few people are working hard to make it happen in our set up, which is really commendable.

\section{REFERENCES}

1. Lundberg GD. How to write a medical paper to get it publish in a good journal. MedGenMed 2005 Nov $4 ; 7(4): 36$.

2. Marusic M, Marusic A. Good editorial practice: editors as educators. Croat Med J 2001 Apr;42(2):113-20.

3. Journology - A New Beginning. J Nepal Med Assoc 2009;48(173):I-I.

4. New Begining. J Nepal Med Assoc 2008;47(172):I-II.

5. Research, publication and young doctors. J Nepal Med Assoc 2007 Jan-Mar;46(165):I-II. 